Article

\title{
Whole Fish Powder Snacks: Evaluation of Structural, Textural, Pasting, and Water Distribution Properties
}

\author{
Asad Nawaz ${ }^{1,2}$, Ibrahim Khalifa ${ }^{3}$, Noman Walayat ${ }^{4}$, Jose M. Lorenzo ${ }^{5,6}{ }^{\mathbb{D}}$, Sana Irshad ${ }^{7}$, Abdullah $^{8}$, \\ Shakeel Ahmed ${ }^{9} \mathbb{D}^{\text {, }}$, Mario Juan Simirgiotis ${ }^{9}$, Madad Ali ${ }^{10}$ and Enpeng Li ${ }^{1,2, *}$
}

1 Jiangsu Key Laboratory of Crop Genetics and Physiology, College of Agriculture, Yangzhou University, Yangzhou 225009, China; 007298@yzu.edu.cn

2 Co-Innovation Center for Modern Production Technology of Grain Crops, Yangzhou University, Yangzhou 225009, China

3 Food Technology Department, Faculty of Agriculture, Benha University, Moshtohor, Benha 13736, Egypt; ibrahiem.khalifa@fagr.bu.edu.eg

4 Department of Food Science and Engineering, College of Ocean, Zhejiang University of Technology, Hangzhou 310014, China; Noman.rai66@gmail.com

5 Centro Tecnológico de la Carne de Galicia, Avd. Galicia no 4, Parque Tecnológico de Galicia, San Cibrao das Viñas, 32900 Ourense, Spain; jmlorenzo@ceteca.net

6 Área de Tecnología de los Alimentos, Facultad de Ciencias de Ourense, Universidad de Vigo, 32004 Ourense, Spain

check for updates

Citation: Nawaz, A.; Khalifa, I.; Walayat, N.; Lorenzo, J.M.; Irshad, S.; Abdullah; Ahmed, S.; Simirgiotis, M.J.; Ali, M.; Li, E. Whole Fish Powder Snacks: Evaluation of Structural, Textural, Pasting, and Water Distribution Properties. Sustainability 2021, 13, 6010. https://doi.org/10.3390/su13116010

Academic Editors:

Miguel Rebollo-Hernanz, Maria Angeles Martín-Cabrejas and Silvia Cañas

Received: 31 March 2021

Accepted: 13 May 2021

Published: 26 May 2021

Publisher's Note: MDPI stays neutral with regard to jurisdictional claims in published maps and institutional affiliations.

Copyright: (C) 2021 by the authors. Licensee MDPI, Basel, Switzerland. This article is an open access article distributed under the terms and conditions of the Creative Commons Attribution (CC BY) license (https:/ / creativecommons.org/licenses/by/ $4.0 /)$.
7 School of Environmental Studies, China University of Geo Sciences, Wuhan 430074, China; sanairshad55@gmail.com

8 College of Biosystems Engineering and Food Science, Zhejiang University, Hangzhou 310058, China; abdullah_ch2002@yahoo.com

9 Instituto de Farmacia, Facultad de Ciencias, Universidad Austral de Chile, Campus Isla Teja, Valdivia 5090000, Chile; Shakeel1177@uach.cl (S.A.); Mario.simirgiotis@uach.cl (M.J.S.)

10 School of Public Affairs, University of Science and Technology of China, Hefei 230026, China; ali12@mail.USTC.edu.cn

* Correspondence: Lep@yzu.edu.cn

\begin{abstract}
Global fisheries production has increased up to $200 \mathrm{MT}$, which has resulted in the intensive generation of waste or byproducts ( 20 MT), which is creating serious problems for environmental management with zero income. This study proposes an idea of using whole fish (red and white meat, skin, bones, and fins but not scales) for human food (snack food) with the aim of zero waste generation. Whole fish powder (WFP) was prepared by a novel method (using freeze-drying as well as stone ball milling) and fortified in baked snacks at four levels $(0,5,10$, and 15\% w/w of $100 \mathrm{~g}$ of formulation). The results revealed that the addition of WFP decreased expansion and color parameters compared to control. Hardness was significantly $(p<0.05)$ increased with the addition of WFP, which was attributed to the mineral content of WFP. Pasting properties determined by rapid visco analyzer (RVA) were dramatically decreased with the addition of 10-15\% WFP, suggesting the weak interaction of starch and protein, which was also evidenced by scanning electron microscopy (SEM). Low field nuclear magnetic resonance (LF-NMR) analysis revealed that the amount of free water was increased when 10-15\% WFP was added in snacks while bound water was highest in control and 5\% WFP samples, respectively. The microstructural analysis by SEM showed that the protein network was increased in those samples incorporated with WFP compared to control that had more starch granules. The results suggest the feasibility of adding $5 \%$ WFP for proper structure, texture, pasting properties, and water distribution in order to reduce fish waste.
\end{abstract}

Keywords: whole fish powder; baked snacks; LF-NMR; SEM; zero waste

\section{Introduction}

Global fisheries production has increased tremendously to 200 MT (37\% increase in the last decade) with aquatic byproducts of $20 \mathrm{MT}$, which are a challenge for blue 
industry [1]. China is the largest producer ( $60 \%$ of world production) of freshwater fish followed by India, Indonesia, and Bangladesh. The utilization of fish for human consumption is $87 \%$ and the rest is used for feed or oil purposes. The increase in fish production has shifted the dieting trends towards more nutritious and healthier food with easy digestibility and high caloric value. However, the processing of fish results in about $30-35 \%$ of fish waste or byproducts [2]. These byproducts can be recovered through different processes to be utilized in food as a functional food or can be used as whole fish in a food. Whole fish is an excellent source of essential nutrients like omega-3 fatty acids, vitamins (A, B, and D), and minerals including calcium, zinc, and phosphorous [3]. It is a complete source of essential amino acids, such as methionine and lysine. Daily protein intake recommended by the WHO (World Health Organization) for humans is $0.7 \mathrm{~g}$ per $\mathrm{kg}$ of body weight per day, while the global market for protein ingredients is predicted to be approximately $\sim 90$ billion USD by 2021, which is mostly determined by the increasing demand for protein-fortified food products [4]. Thus, the introduction of whole fish in food can be a prime choice for consumers as well as being one step toward zero waste generation.

The fishery industries produce a huge amount of scales, bones, fins, and skin as waste or byproducts. This waste causes pollution and a bad odor if dumped without treatment [5]. The nutritional values of these discards are high, therefore, these byproducts are potentially valuable resources with respect to their utilization in food. However, pretreatment of these parts is needed in order to make them suitable for food purposes, despite its use in fishmeal manufacturing [6]. Different foods, such as cookies and crackers, are suitable for consumers due to their wide range of preferences; they can be appreciated as a snack with a long shelf life and low cost, thus having a great economic importance [7]. The quality of cookies depends on their ingredients, processing methods, and physio-chemical characteristics [8]. Efforts are being made to modify the nutritional value of snacks and different ingredients, such as red fish meat [9], fish bone [10], potato powder [11], starches [12], and fish protein isolates [13]. Regarding the protein source, fish meat is considered a good source of protein owing to its high biological value and quality of essential amino acids [9]. Since snacks are believed to be a good carrier of nutrition, it is also important to supply micronutrients in order to maintain balanced nutrition. Thus, the idea of adding whole fish into snacks has a potential application.

Previous studies have reported small fish [14] as a nutritional prospective and added whole fish [15] in different foods, including snacks [16]. Moreover, fish bone and fish meat [10], red fish meat [9], and fish protein isolate [13] have been reported in snacks; however, no one has used whole fish or whole fish powder in snacks. Furthermore, protein concentrate or protein isolate have been prepared by heating methods, while no study has utilized the freeze-drying of whole fish powder. In addition to this, most authors used the frying method, which resulted in excessive oil uptake in the case of the addition of fish meat to snacks [2]. Thus, an oil-free method such as baking can be a prime choice for better physio-chemical properties.

Therefore, the prime objective of present study was to prepare whole fish powder using freeze-drying and stone ball milling for its use as fortification in snack food which has not been reported before. The freeze-drying of minced meat was done as a pretreatment to avoid denaturation while stone ball media milling was used to minimize the heat produced during milling. The effect of adding different ratios of whole fish powder on physiochemical, microstructural, pasting, and textural properties of snacks prepared using the baking method was investigated. In addition, the water distribution of snacks was analyzed using LF-NMR. The study provides a reference for an initiative of adding whole fish into snacks as well as a solution for blue industries to minimize waste or byproducts. 


\section{Materials and Methods}

\subsection{Materials}

Whole wheat flour (protein 12\%, moisture 11\%, and fat $2 \%$ ) and salt were purchased from the supermarket of Huazhong Agriculture University, Wuhan, Hubei China (HZAU). Grass carp (Ctenopharyngodon idella) (weight $\sim 3 \mathrm{~kg}$, deceased form) was purchased from HZAU. The fish was manually cleaned and filleted and fins were removed using a knife. All chemicals used in this study were of analytical grade and purchased from Sigma-Aldrich, Inc. (Natick, MA, USA).

\subsection{Micro Size Whole Fish Powder}

Whole fish pieces (including bones, skin, and flesh), $500 \pm 50 \mathrm{~g}$, were minced in a commercial meat mincer (Model: Hr-12MD, Spaghetti Straws Making Machine Manufacture, Zhejiang China) and passed through the sieve with a $1 \mathrm{~mm}$ mesh. The minced whole fish was placed in Petri dishes and freeze-dried using a freeze-dryer (Model: 6KBTES-55, VirTis, SP Scientific, Warminster, PA, USA) at $-70{ }^{\circ} \mathrm{C}$ for $48 \mathrm{~h}$. The dried powder was further subjected to micronization which was done using a stone ball milling machine (Planetary type ball mill, QM-ISP2-CL, Instrument Factory of Nanjing University, China). This ball milling was done to keep the temperature of the whole fish powder low in order to avoid any denaturation of the powder due to heat induced. Agate balls $(2 \mathrm{~mm})$ at a ratio of (5:1) were added in an agate grinding bowl $(50 \mathrm{~mL})$ for ball milling purposes. The fiber fractions were then ground at $500 \mathrm{rpm}$ for $12 \mathrm{~h}$ using agate balls to reduce the average particle size (the milling process was optimized after applying various ratios, speed, and time, the data are not shown here and are in the process of publication elsewhere). After the ball milling process, the micronized powder was stored at $0-4{ }^{\circ} \mathrm{C}$ in airtight zipped bags until further analysis. The particle size of the whole fish powder, measured using Mastersize2000, Malvern Instruments Ltd., Worcestershire, UK was estimated to be $25 \mu \mathrm{m}$ following the method of Nawaz et al. [10]. The proximate composition of whole fish powder was protein $73 \%$, fat $11 \%$, and ash $14 \%$, while moisture and carbohydrates contents were less than $1 \%$.

\subsection{Preparation of Snacks}

Wheat flour $(80 \% w / w)$, potato powder $(20 \% w / w)$, and whole fish powder were mixed together in a mixing bowl for a control sample. Subsequently, 0, 5, 10, and 15\% WFP were added by replacing with wheat flour, thus making 4 treatments. All ingredients including tri-calcium phosphate $(0.03 \%)$, water $(32 \mathrm{~g} / 100 \mathrm{~mL}$ of wheat flour), and salt $(1.5 \%)$ were added to each sample and kneaded manually for 5 min to obtain a uniform dough following the method of our previous study [9]. The dough was hydrated (at $25^{\circ} \mathrm{C}$ for $30 \mathrm{~min}$ ) and rolled several times using a noodle maker roller machine (FKM-180, Yongkang Electrical Appliances Co., Ltd., Yongkong, Hebei, China) so the thickness of the sheet became uniform $(\sim 3 \mathrm{~mm})$. The sheet was further shaped into pieces of $3 \times 3 \mathrm{~cm}^{2}$. The snack pieces were baked at $220^{\circ} \mathrm{C}$ for $6 \mathrm{~min}$ in a baking oven that was thermostatically controlled. The baked snacks were stored at $20^{\circ} \mathrm{C}$ in high density polyethylene bags (HDPE) for further analysis. For each treatment, $\sim 2 \mathrm{~kg}$ of snacks were prepared.

\subsection{Expansion}

The expansion of the baked snacks was measured before and after baking following the methodology of Nawaz et al. [10]. Snack pieces were marked with permanent ink and readings were done using a digital Vernier caliper. Six replications were made for each treatment and mean values are reported.

\subsection{Proximate Composition}

Proximate composition, including moisture, protein, fat, ash, and carbohydrates, was calculated using AOAC standard methods. The following method Nos. were adopted for proximate analysis: moisture (method No. 934.06), fat (method No. 920.153), protein (method No. 976.05), and ash (method No. 942.05). The estimation of proximate 
carbohydrate was done by subtracting the moisture, crude protein, crude lipids, and ash content from $100 \%$. For all treatments, all measurements were performed in triplicate and mean values are reported. Water holding/hydration capacity (WHC) was assessed using a centrifugation method following the protocol of Nawaz et al. [9]. Briefly, a $2 \mathrm{~g}$ sample (powder) of snacks was added into $30 \mathrm{~mL}$ of water in a pre-weighted centrifuge tube at room temperature for $25 \mathrm{~min}$. After this, centrifugation was done at $1000 \times g$ for $15 \mathrm{~min}$. The excessive water was carefully discarded. The calculation was done using the following formula:

WHC (g.g $\left.{ }^{-1}\right)=($ weight of tube + weight of sediment $)-$ weight of tube/weight of sample.

WHC was measured in triplicate for each sample and mean values are reported.

\subsection{Texture Profile Analysis}

The TPA of baked snacks was done following the methodology of Nawaz et al. [17] using a 3-Point Bending Rig probe (HDP/3PB) and TA-XT plus texture analyzer (Stable Micro Systems, surrey, UK) with a $5 \mathrm{~kg}$ load cell. The following conditions were used at the time of the TPA analysis: test mode: compression; pre-test and posttest speed: 1.00 and $10.00 \mathrm{~mm} / \mathrm{s}$, respectively; trigger type: auto; trigger force: $5.0 \mathrm{~g}$, texture variable No: 5: 0.0 g; target mode: distance; distance: $5 \mathrm{~mm}$. The mean distance and peak force $(\mathrm{N})$ at break were calculated. The reported values for hardness are an average of five replicates.

\subsection{Color Analysis}

The color analysis of the baked snacks was done using a CR-300 Minolta colorimeter (Osaka, Japan) and following the protocol of Nawaz et al. [9]. This was done after grinding the snacks and passing them through a 100-mesh sieve. Measurements were done in triplicates and mean values are reported. Lightness $\left(L^{*}\right)$, redness $\left(a^{*}\right)$, and yellowness $\left(b^{*}\right)$ were noted for each sample.

\subsection{Pasting Properties of Baked Snacks}

The pasting properties of the baked snacks were determined following the method of Nawaz et al. [9] using a 4-series (RVA) rapid visco analyzer (Newport Scientific Pvt., Ltd., Narrabeen, NSW, Australia). These were measured in triplicate for each sample and mean values are reported.

\subsection{Water Distribution/LF-NMR}

The water distribution of the baked snacks was determined using LF-NMR following the method of Nawaz et al. [17], using a Minspec mq 20 Low-field pulsed NMR spectrometer (Bruker, Ettlingen, Germany). The transverse relaxation time $\left(T_{2}\right)$ was measured at $25^{\circ} \mathrm{C}$ and $20 \mathrm{MHz}$, which was done by means of a sequence based on Carr-PurcellMeiboom-Gill (CPMG). The amounts of protons in the population were proportional to the obtained peaks.

\subsection{Scanning Electron Microscopy (SEM) Analysis}

A SEM analysis of baked snacks was done using SEM (Model: JSM-6390LV; NTC, Tokyo, Japan) and following the methodology of Nawaz et al. [18] and Walayat et al. [19]. Baked samples were subjected to freeze-drying by means of a freeze-dryer (Model: 6KBTES55 , VirTis, SP Scientific, Warminster, PA, USA) for $48 \mathrm{~h}$ at $-70^{\circ} \mathrm{C}$. Freeze-dried pieces of snack were attached (using double stick tape) on an aluminum slid and coating of platinum was done prior to analysis. The samples were scanned with a magnification of 1000 and an accelerating voltage of $15 \mathrm{kV}$. 


\subsection{Statistical Analysis}

Statistical analysis was done using SPSS software (SPSS Inc., Chicago, IL, USA) and graphs were plotted using Origin Pro 9. Data were analyzed using one-way analysis of variance (ANOVA) and Duncan's multiple range tests at a significant level of $p<0.05$.

\section{Results and Discussion}

\subsection{Expansion and Water Holding Capacity}

The results of the expansion and WHC of baked snacks are displayed in Figure 1. A significant $(p<0.05)$ difference was observed between control and WFP snacks. The expansion decreased with the increase in WFP and was highest in the control sample. The lower expansion was attributed to the WFP (containing collagen and hydroxyapatites) and the replacement of gluten protein, which has elastic properties upon heating. In addition to this, WFP, compared to wheat flour, has less or negligible starch content, which has high WHC compared to meat as reported by Nawaz et al. [10]. Similarly, the same study reported decreased expansion due to the addition of fish bone while fish meat increased expansion but not as high as in control, which was devoid of fish meat and bone, contradicting, however, the same study by Nawaz et al. [10]; expansion values reported in that study were higher than this study. This might be due to the cooking method (frying) in that study compared to this study (baking). In addition, the study by Shah et al. [12] reported decreased expansion due to the addition of minced fish meat in corn-fish snacks but no study was found that tested the addition of WFP-based snacks. However, after adding a relatively high amount, 10-15\% WFP, the expansion was further decreased, even less than the $70 \%$ that is required for snacks.

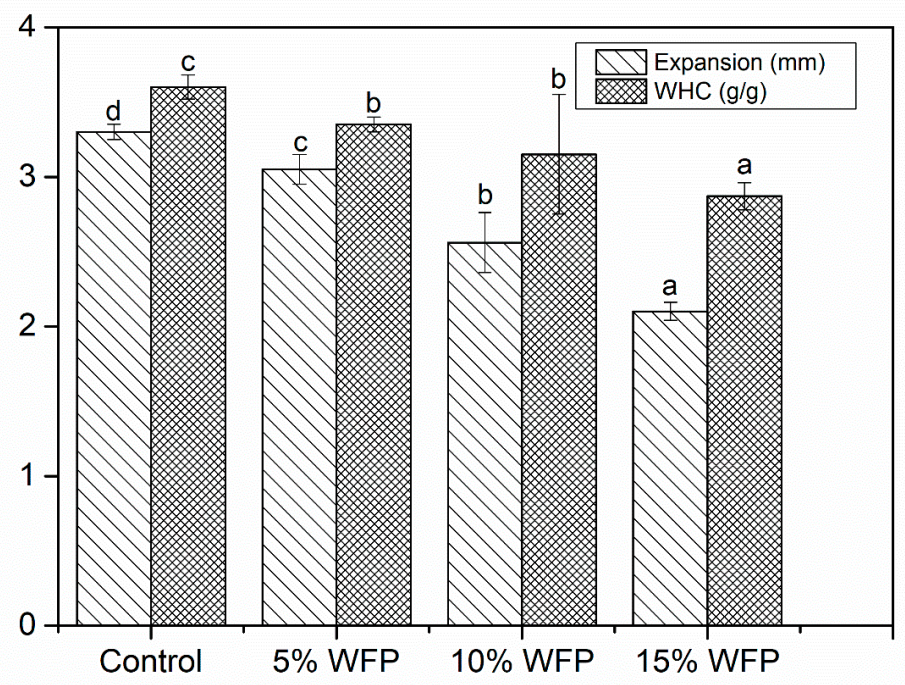

Figure 1. The expansion and water hydration capacity of baked snacks prepared with different levels of whole fish powder (WFP). Different letters over the error bars represent the significant difference at $p<0.05$ using Duncan's multiple range test.

The results of WHC of the baked snacks are shown in Figure 1, revealing the same trend as seen for expansion. The highest WHC being in the control sample is attributed to the characteristics of the starch-based material that is high in control. The results of the current study are in accordance with Allen et al. [20] and Singh et al. [21] who reported that WHC decreased when protein content increased in snack-based products. Similarly, WHC decreased as the level of fish protein increased in protein-fortified pasta [13]. Moreover, the addition of red beans (a high protein source) also decreased the WHC of puffed snacks [22]. The decreased WHC in WFP snacks could be due to the development of a protein network that wrapped the starch molecules, which resulted in less space, improper gelatinization, and reduced expansion. Inferring from these results, it can be concluded that WFP, a 
complex of hydroxyapatites and myofibril proteins, can be added up to the range of 5-10\% in snacks for a better expansion and structure.

\subsection{Proximate Composition}

The proximate composition of the snacks is displayed in Table 1. The moisture content increased when WFP increased and was found to be highest at $15 \%$ WFP, suggesting that extra moisture in the dough may not have been totally removed during baking process. However, this increase was not statistically significant when WFP increased from 10 to $15 \%$. Fat content increased with the addition of WFP, indicating the compositional difference between the control and the WFP snacks. In addition, WFP has a higher fat content than wheat flour owing to the fact that fish meat and fish bones have a high percentage of fat. Since no pretreatment (heating or autoclave for bones) was done, no fat globules seeped out during the preparation of WFP. Therefore, the addition of WFP caused a high fat content. The increase in ash content with the addition of WFP was obvious from the composition of WFP having bones (hydroxyapatites and collagen) with high ash content as reported previously [10]. Crude protein assessed by the Kjeldhal method increased in WFP-based snacks with the increase of WFP. A high level of WFP (indeed, high protein) decreased expansion and air cell size while increasing the bulk density of snacks, which was also evidenced from low expansion and WHC in WFP-based snacks. There could be another possibility, which is that the addition of this protein was not glutinous, which resulted in less expansion as gluten protein has more extensibility upon heating [23]. Carbohydrate contents decreased gradually with the increase of WFP and were statistically significant in all treatments.

Table 1. Physio-chemical properties of baked snacks prepared with different levels of whole fish powder (WFP).

\begin{tabular}{ccccc}
\hline Samples & Control & $\mathbf{5 \%}$ WFP & $\mathbf{1 0 \% W F P}$ & $\mathbf{1 5 \% W F P}$ \\
\hline Moisture (\%) & $9.32 \pm 1.04^{\mathrm{a}^{*}}$ & $10.85 \pm 0.34^{\mathrm{b}}$ & $11.85 \pm 0.64^{\mathrm{c}}$ & $12.32 \pm 1.23^{\mathrm{c}}$ \\
Fat (\%) & $1.45 \pm 0.14^{\mathrm{a}}$ & $1.95 \pm 0.44^{\mathrm{b}}$ & $2.35 \pm 0.14^{\mathrm{c}}$ & $3.54 \pm 0.21^{\mathrm{d}}$ \\
Ash (\%) & $0.94 \pm 0.32^{\mathrm{a}}$ & $2.43 \pm 1.04^{\mathrm{b}}$ & $5.65 \pm 1.11^{\mathrm{c}}$ & $7.86 \pm 0.78^{\mathrm{d}}$ \\
Protein (\%) & $11.25 \pm 1.76^{\mathrm{a}}$ & $14.23 \pm 0.04^{\mathrm{b}}$ & $17.11 \pm 0.04^{\mathrm{c}}$ & $19.56 \pm 0.04^{\mathrm{d}}$ \\
Carbohydrates (\%) & $78.49 \pm 1.02^{\mathrm{d}}$ & $70.54 \pm 2.64^{\mathrm{c}}$ & $63.25 \pm 3.58^{\mathrm{b}}$ & $56.76 \pm 1.54^{\mathrm{a}}$ \\
$L^{*}$ & $89.75 \pm 0.53^{\mathrm{d}}$ & $86.77 \pm 0.23^{\mathrm{c}}$ & $81.52 \pm 1.23^{\mathrm{b}}$ & $80.86 \pm 0.33^{\mathrm{a}}$ \\
$a^{*}$ & $0.89 \pm 0.04^{\mathrm{a}}$ & $1.50 \pm 0.14^{\mathrm{b}}$ & $1.96 \pm 0.23^{\mathrm{c}}$ & $2.40 \pm 0.17^{\mathrm{d}}$ \\
$b^{*}$ & $13.20 \pm 0.84^{\mathrm{a}}$ & $16.70 \pm 0.34^{\mathrm{b}}$ & $17.70 \pm 0.44^{\mathrm{c}}$ & $18.59 \pm 0.74^{\mathrm{c}}$ \\
TPA (N) & $40.52 \pm 2.30^{\mathrm{a}}$ & $44.55 \pm 1.30^{\mathrm{b}}$ & $46.32 \pm 2.70^{\mathrm{c}}$ & $47.32 \pm 2.90^{\mathrm{c}}$
\end{tabular}

${ }^{*}$ Different letters in columns represent the significant difference at $p<0.05$ using Duncan's multiple range test. WFP $=$ whole fish powder.

\subsection{Texture Profile Analysis}

Texture is an important concern for consumers as well as the snack industry. The texture of fish meat either during storage or after processing is of high interest. The results for TPA in terms of hardness are displayed in Table 1. WFP showed significantly higher hardness than control, while the lowest hardness was observed in the control sample. However, this increase was not statistically significant between 10 and $15 \%$ WFP. The increased hardness in WFP-based snacks was attributed to the hydroxyapatites and complex collagen matrix. WFP has more inorganic portions and high protein that wrapped the starch granules and inhibited the granules from swelling, thus making them compact. In fact, expansion, and hardness are negatively correlated: as expansion increases, the hardness decreases. Expansion is related to bubble formation and more intercellular spaces in a heterogeneous system, resulting in low bulk density and low hardness. Thus, the results of expansion can be interpreted with hardness: WFP decreased the expansion of snacks, ultimately resulting in extraordinary hardness. On one hand, some authors reported decreased hardness due to the addition of myofibril proteins that associate into gel upon heating [21,24], while on the other hand, Abdel-Moemin [25] reported the increased 
hardness of cookies with the addition of fish bones. Inferring from the results and previous studies, it can be concluded that the effect of fish bone was more dominant in snacks compared to that of fish meat. Another possibility is that a higher amount of WFP resulted in extraordinary hardness, which is also unacceptable from a consumer point of view.

\subsection{Color Parameters}

Color is another important attribute with respect to consumer acceptability, as an appealing color is the first impression of an end product. The results of the color parameters of baked snacks are shown in Table 1 . Among the color parameters, lightness $\left(\mathrm{L}^{*}\right)$ was higher in the control sample, which gradually decreased with the addition of WFP. On the other hand, redness $\left(a^{*}\right)$ and yellowness $\left(b^{*}\right)$ increased with the increased amount of WFP, while the opposite trend was observed in control sample. The decreased $\mathrm{L}^{*}$ was attributed to the red color of WFP, which increased the redness and yellowness in accordance with previous reports [24-26]. The color changes in WFP snacks were attributed to the Maillard reaction between reducing sugars and amino acids present in the formulation. In addition, wheat flour has a more yellow color/appearance than those of WFP, which attributed to the compositional difference.

\subsection{Pasting Properties}

The gelatinization properties of starch in a heterogeneous system are of high interest and determine the stability and structural attributes of the end product. The starch granules, which have not been gelatinized, are mainly present as microcrystals, are mainly connected by hydrogen bonds in the middle, and are insoluble in water at room temperature [18]. Upon heating, these lose their crystalline structure, and this can be better predicted by pasting properties, such as peak viscosity, final viscosity, setback, and pasting temperature.

The findings regarding the pasting properties of the baked snacks are presented in Table 2 and Figure 2. Peak viscosity, which indicates the strength of the binding ability at molecular level, decreased with the increase of WFP and even decreased more drastically when 10 to $15 \%$ WFP was added to the snacks. This suggests that a high amount of WFP destabilizes the strength of the snacks, which was also evident from low expansion and WHC results. Moreover, this pronounced decrease in peak viscosity upon the addition of a high amount of WFP indicated the weak interaction between starch and WFP. Furthermore, this was more obvious in Figure 2, in which 10 and 15\% WFP addition showed lowest peak viscosity. Breakdown viscosity represents the strength of granules while final viscosity and setback indicate the degree of rearrangement of starch granules, which determine the transformation form from viscous liquid to gel. The breakdown and final viscosities of the control sample were significantly higher while these decreased reasonably when WFP was added. However, 10 and 15\% WFP did not show any statistically significant difference, suggesting a negligible difference in the structural and physiochemical properties of these two samples. These decreased viscosities showed the weak interaction between the starchprotein matrix. These results are in accordance with a previous study [17], in which all these viscosities decreased in the control sample (having fish meat) while the addition of emulsifiers increased the corresponding values. However, the sudden decrease in the values of all viscosities was only attributed to WFP that was a mixture of collagen, hydroxyapatite, myofibril proteins, and an inorganic portion. However, as indicated in [17], this could be overcome with the use of emulsifiers or hydrocolloidal agents [27]. The pasting temperature indicates the measure of the lowest temperature that is required to cook a food. From Table 2, it is obvious that the pasting temperature increased with the increase of WFP. Generally, low pasting time is encouraged with respect to cost and energy in food industry. The possible reason for the increase of pasting temperature might be minerals that have high boiling points. This was further evidenced in the study [9] that reported the low pasting temperature of snacks in control (wheat flour and potato powder). This was further proven only for starch, which also has a lower pasting temperature [18]. 
Thus, from the results of the pasting properties, it was observed that only $5 \%$ addition of WFP showed good structural and gelling properties.

Table 2. Pasting properties of baked snacks prepared with different levels of whole fish powder (WFP).

\begin{tabular}{|c|c|c|c|c|c|c|}
\hline Samples & $\begin{array}{l}\text { Peak Viscosity } \\
\text { (RVU) }\end{array}$ & $\begin{array}{l}\text { Trough } \\
\text { Viscosity } \\
\text { (RVU) }\end{array}$ & $\begin{array}{c}\text { Breakdown } \\
\text { Viscosity } \\
\text { (RVU) }\end{array}$ & $\begin{array}{c}\text { Final } \\
\text { Viscosity } \\
\text { (RVU) }\end{array}$ & $\begin{array}{c}\text { Setback } \\
\text { (RVU) }\end{array}$ & $\begin{array}{c}\text { Temperature } \\
\left({ }^{\circ} \mathrm{C}\right)\end{array}$ \\
\hline Control & $568 \pm 23.34^{d}$ & $464 \pm 06.75^{c}$ & $104 \pm 16.89^{b *}$ & $891 \pm 53.37^{d}$ & $427 \pm 41.68^{\mathrm{d}}$ & $91.35 \pm 0.31^{\mathrm{a}}$ \\
\hline $5 \%$ WFP & $491 \pm 43.22^{c}$ & $456 \pm 13.37^{c}$ & $25 \pm 10.63^{a}$ & $782 \pm 26.63^{b}$ & $316 \pm 13.82^{c}$ & $92.85 \pm 0.13^{b}$ \\
\hline 10\%WFP & $192 \pm 23.59^{a}$ & $180 \pm 63.12^{a}$ & $12 \pm 23.55^{\mathrm{a}}$ & $420 \pm 31.46^{a}$ & $228 \pm 37.79^{b}$ & $95.25 \pm 0.24^{c}$ \\
\hline $15 \% W F P$ & $231 \pm 26.78^{b}$ & $226 \pm 16.31^{b}$ & $10 \pm 13.91^{\mathrm{a}}$ & $415 \pm 26.71^{\mathrm{a}}$ & $183 \pm 15.83^{a}$ & $94.72 \pm 0.47^{c}$ \\
\hline
\end{tabular}

* Different letters in columns represent the significant difference at $p<0.05$ using Duncan's multiple range test. WFP $=$ whole fish powder.

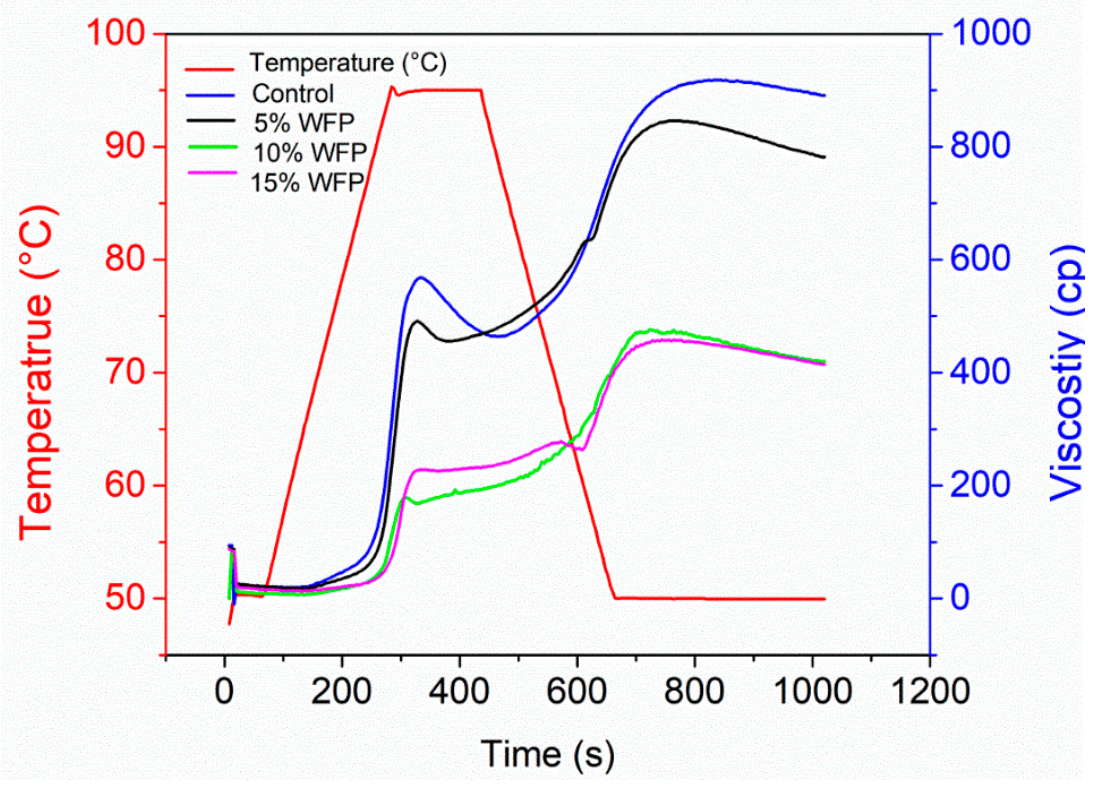

Figure 2. Pasting properties of baked snacks prepared with different ratios of whole fish powder.

\subsection{LF-NMR Analysis}

The variations in water mobility and distribution throughout thermal processing are of great interest regarding the physio-biochemical status, quality, taste, and texture of end products. Water mobility changes can be determined using the values of relaxation time $\left(\mathrm{T}_{2}\right)$ using NMR analysis. This relaxation time $\left(\mathrm{T}_{2}\right)$ is distributed into 3 modes: $\mathrm{T}_{21}$ (0.1-1 ms) attributed to tightly bound water, $\mathrm{T}_{22}(1-100 \mathrm{~ms})$ indicates immobilized water, and $\mathrm{T}_{23}(100-1000 \mathrm{~ms})$ represents unbound water [28]. Commonly, a short relaxation time and amplitude indicate a strong association between solids and water in a matrix, whereas a long relaxation time and amplitude show the weak bond between water and solids in a heterogeneous system. Figure 3 represents the water distribution for baked snacks using various levels of WFP and the control sample. The relaxation time and amplitude $\left(T_{21}\right)$ were shortest in 5\% WFP snacks, indicating the presence of more bound water in the matrix. The immobilized water (1-100 ms) was highest in 10 and 15\% WFP-based samples as relaxation time and amplitude of $\mathrm{T}_{22}$ were highest in 10 and $15 \%$ samples. This suggests that $5 \%$ WFP was favorable for a proper starch-protein interaction while the addition of a high amount resulted in a weak interaction between starch granules and complex WFP, which has fat, protein, and collagen from bones. Meanwhile, amplitude peaks for $\mathrm{T}_{23}$ were in the following order: $15 \%>10 \%>5 \%$ WFP > control. This suggests that the highest proportion of unbound water was present in those samples with high amounts of WFP, while control and 5\% showed the least amount of unbound water. The shortest relaxation 
time for 5\% WFP might be due to the strong bound water within the quaternary and tertiary structure of protein. This further suggests that with the addition of $5 \%$ WFP, water inside the matrix was not leached out during thermal processing, whereas a high amount of WFP did not favor the water binding in the matrix. Similarly, the proton population in the $\mathrm{T}_{22}$ region appeared to be more sufficient in 5\% WFP samples than in 10 and $15 \%$ WFP samples, which suggests that less mobile water was released. This is further explained by the phenomenon that during the thermal process of dough, water acts as a plasticizer and endorses interaction among the molecules of starch and protein. In 10 and 15\%WFP samples, a longer relaxation time was noticed, which might be due to the water located outside the mayofibrillar proteins and collagen network, which was leached out during heating. On the other hand, in control and 5\% WFP, this water was bounded due to the strong interaction of starch and protein molecules. Upon the addition of 10 or $15 \%$ WFP, this interaction became weaker, which resulted in a high amount of free and unbound water. These results were supported by the study by Li et al. [29] and Walayat et al. [19,30] who reported that free water from mayofibrillar protein leached out during heating. Thus, it was revealed that the addition of 5\% WFP increased the binding of water in the matrix.

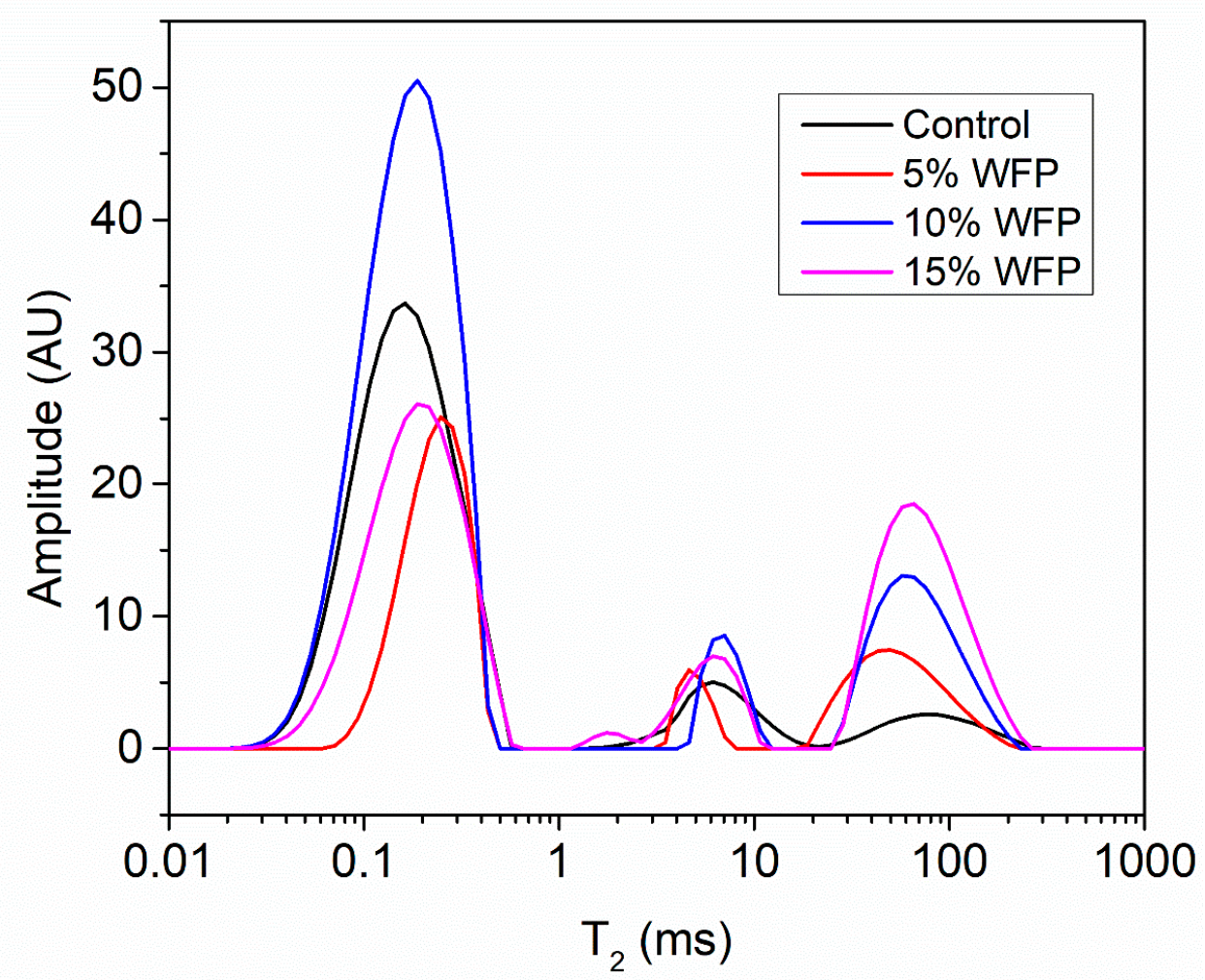

Figure 3. LF-NMR analysis of baked snacks prepared with different ratios of whole fish powder.

These results correlate with the results of WHC that decreased with the addition of 10 or $15 \%$ WFP. This was further supported by SEM images suggesting a weak starchprotein network. In addition to this, there is no study available on the water distribution of snacks with special reference to WFP. Our research is the first study that reports the water distribution of baked snacks based on WFP.

\subsection{Microstructure}

The microstructure or internal structure of an end product gives the exact information of the heterogeneous system. It is an important concern in understanding the interaction of different components. The results of SEM analysis are shown in Figure 4. The images reveal that the control sample had a high portion of starch granules, suggesting the dominance of starch over the protein network, in accordance with the results of the proximate analysis, 
especially the protein content. In addition to this, large-sized starch granules were observed signifying the proper gelatinization, which was also evident from the high WHC of the control sample compared to the other samples. Moreover, this proper gelatinization was also supported by the results of high expansion for the control sample compared to WFP snacks. However, as WFP increased, the protein matrix increased, which was more pronounced in 15\% WFP having a high portion of protein, while for the control sample, fewer and small-sized starch granules were observed, suggesting less gelatinization of the starch. This was due to the dominance of protein from WFP that wrapped the starch granules. The addition of 5\% WFP resulted in a uniform structure with a reasonable number of starch granules and a protein matrix. However, the increased protein of WFP resulted in non-uniform holes and an irregular structure, which was also in accordance with pasting properties that showed a sudden decrease in all viscosities and a weak interaction of the starch-protein matrix. These results inferred that a balanced percentage of protein is necessary for snack structure.

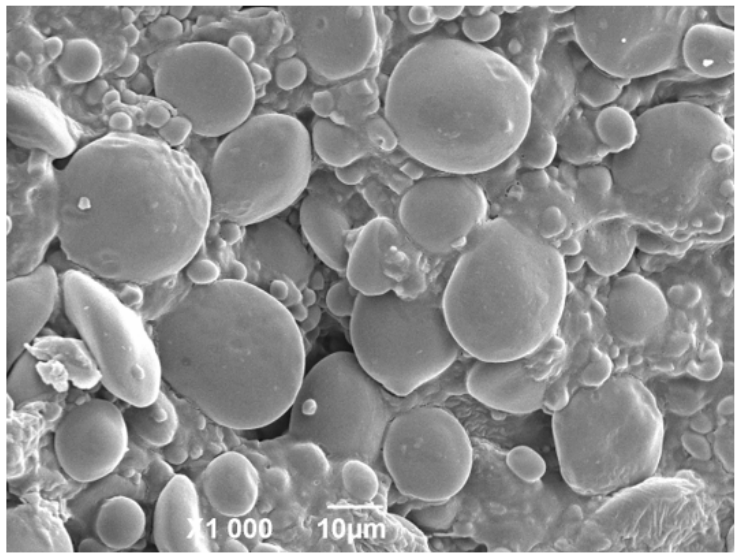

Control

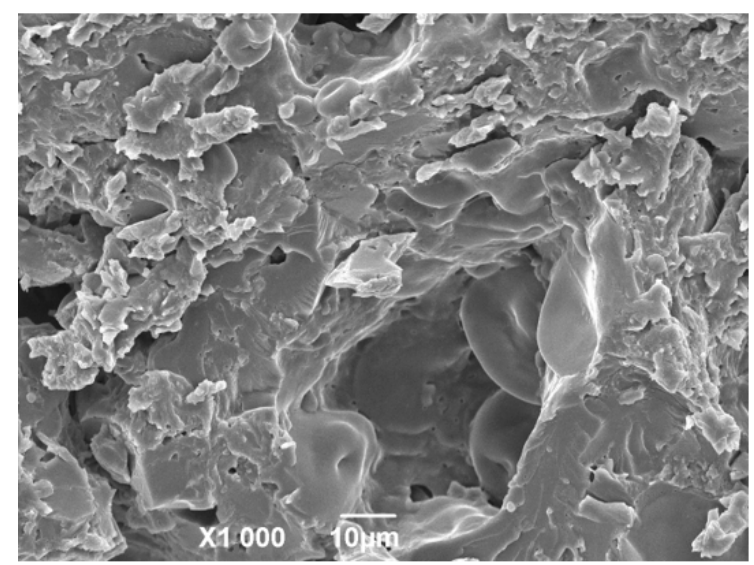

$10 \%$ WFP

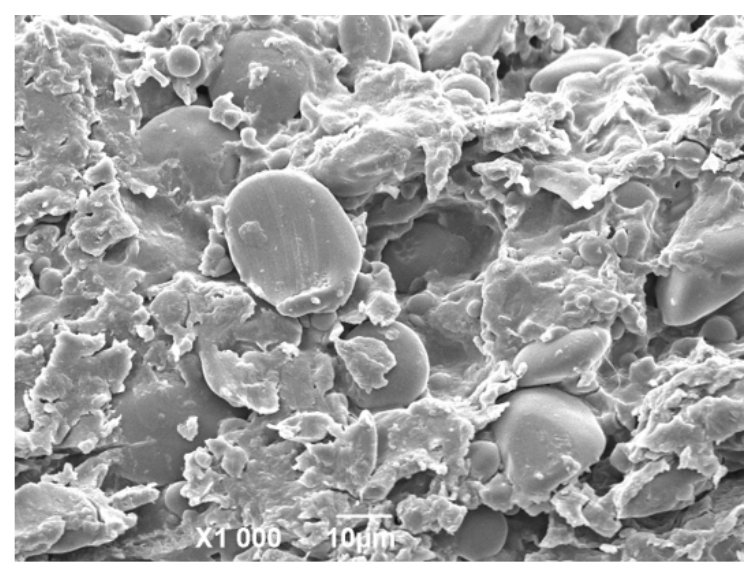

$5 \%$ WFP

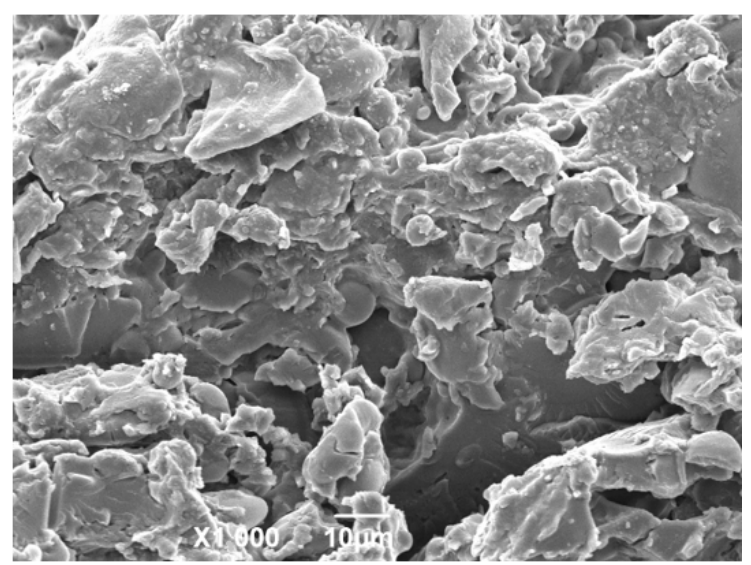

$15 \%$ WFP

Figure 4. The microstructure of baked snacks prepared with different ratios of whole fish powder.

\section{Conclusions}

WFP was prepared by a novel method and successfully used to fortify baked snacks. The results showed some meaningful conclusions that might be helpful in order to promote the best possible use of whole fish instead of fillet processing or fortification. However, a high amount of WFP is not acceptable in snacks, which was supported by the results of WHC, TPA, RVA, and LF-NMR analysis in the present study. Using WFP, the deficiency of micronutrients and malnutrition can be overcome. This will not only use the low value byproducts (bones and skin) of the filleting industry but also help to reduce the waste of 
fisheries industries, which is mostly dumped with the intention of using it for fertilizer or feed prospective (low income). This study is also useful in determining the proper amount of WFP for snack preparation on an industrial scale. According to the findings, the present study recommends 5\% WFP in snacks but this can be further increased using different food hydrocolloids, such as emulsifiers and food additives, which is also a future direction of this study. Since this is an initiative toward the use of WFP and has potential for its commercial-scale application, there is a lot of work that is still needed. For example, the investigation of storage stability or shelf life and sensory characteristics is needed in order to commercialize this product. The in vitro digestibility of WFP is a big concern—although studies have reported the in vitro digestibility of fish meat protein, as a whole, in vitro or in vivo studies of WFP are lacking in the literature. With all these concerns, the addition of WFP not only in snacks but also in bakery and other commercial products will be an encouraging step that will not only decrease malnutrition but also encourage the best use of these byproducts.

Author Contributions: Conceptualization and writing original draft, A.N.; methodology, N.W.; validation, S.I.; formal analysis validation, S.A. and M.J.S.; investigation, A.; review and editing, I.K. and J.M.L.; statistical analysis and software, M.A.; supervision, E.L. All authors have read and agreed to the published version of the manuscript.

Funding: This work was financially supported by Postdoc funding from Yangzhou University, Yangzhou, Jiangsu, China. We greatly acknowledge the support of Jiangsu provincial Entrepreneurial and innovation PhD program, a Yangzhou lvyangjinfeng talent program (Engpeng Li), a natural science foundation of China Grant (C1304013151101138).

Data Availability Statement: The data is openly available for all readers.

Acknowledgments: This work was financially supported by Postdoc funding of Yangzhou University, Yangzhou, Jiangsu, China. We greatly acknowledge the support of Jiangsu provincial Entrepreneurial and innovation PhD program, and a Yangzhou lvyangjinfeng talent program (Enpeng $\mathrm{Li})$, a natural science foundation of China Grant (C1304013151101138).

Conflicts of Interest: The authors declare no conflict of interest.

\section{References}

1. FAO. State of World Fisheries and Aquaculture 2016 (French); Food \& Agriculture Organization: Rome, Italy, 2016.

2. Ishak, N.H.; Sarbon, N.M. A review of protein hydrolysates and bioactive peptides deriving from wastes generated by fish processing. Food Bioprocess Technol. 2018, 11, 2-16. [CrossRef]

3. Khalili Tilami, S.; Sampels, S. Nutritional value of fish: Lipids, proteins, vitamins, and minerals. Rev. Fish. Sci. Aquac. 2018, 26, 243-253. [CrossRef]

4. Mittendorfer, B.; Klein, S.; Fontana, L. A word of caution against excessive protein intake. Nat. Rev. Endocrinol. 2020, 16, 59-66. [CrossRef] [PubMed]

5. Nawaz, A.; Li, E.; Irshad, S.; Xiong, Z.; Xiong, H.; Shahbaz, H.M.; Siddique, F. Valorization of fisheries by-products: Challenges and technical concerns to food industry. Trends Food Sci. Technol. 2020, 99, 34-43. [CrossRef]

6. Olsen, R.L.; Toppe, J.; Karunasagar, I. Challenges and realistic opportunities in the use of by-products from processing of fish and shellfish. Trends Food Sci. Technol. 2014, 36, 144-151. [CrossRef]

7. Reddy, V.; Urooj, A.; Kumar, A. Evaluation of antioxidant activity of some plant extracts and their application in biscuits. Food Chem. 2005, 90, 317-321. [CrossRef]

8. Ndiritu, A.K.; Kinyuru, J.N.; Kenji, G.M.; Gichuhi, P.N. Extraction technique influences the physico-chemical characteristics and functional properties of edible crickets (Acheta domesticus) protein concentrate. J. Food Meas. Charact. 2017, 11, $2013-2021$. [CrossRef]

9. Nawaz, A.; Xiong, Z.; Li, Q.; Xiong, H.; Irshad, S.; Chen, L.; Wang, P.; Zhang, M.; Hina, S.; Regenstein, J.M. Evaluation of physicochemical, textural and sensory quality characteristics of red fish meat-based fried snacks. J. Sci. Food Agric. 2019, 99, 5771-5777. [CrossRef] [PubMed]

10. Nawaz, A.; Xiong, Z.; Xiong, H.; Chen, L.; Wang, P.-k.; Ahmad, I.; Hu, C.; Irshad, S.; Ali, S.W. The effects of fish meat and fish bone addition on nutritional value, texture and microstructure of optimised fried snacks. Int. J. Food Sci. Technol. 2019, 54, 1045-1053. [CrossRef]

11. Nawaz, A.; Xiong, Z.; Li, Q.; Xiong, H.; Liu, J.; Chen, L.; Wang, P.; Walayat, N.; Irshad, S.; Regenstein, J.M. Effect of wheat flour replacement with potato powder on dough rheology, physiochemical and microstructural properties of instant noodles. J. Food Process. Preserv. 2019, 43, e13995. [CrossRef] 
12. Shah Mohammadi, H.R.; Bakar, J.; Russly, A.R.; Noranizan, M.A.; Mirhosseini, H. Puffed Corn-Fish Snack Development by Extrusion Technology. Iran. J. Fish. Sci. 2014, 13, 748-760.

13. Desai, A.; Brennan, M.A.; Brennan, C.S. The effect of semolina replacement with protein powder from fish (Pseudophycis bachus) on the physicochemical characteristics of pasta. LWT 2018, 89, 52-57. [CrossRef]

14. Abbey, L.; Glover-Amengor, M.; Atikpo, M.O.; Atter, A.; Toppe, J. Nutrient content of fish powder from low value fish and fish byproducts. Food Sci. Nutr. 2017, 5, 374-379. [CrossRef] [PubMed]

15. Larsen, T.; Thilsted, S.H.; Kongsbak, K.; Hansen, M. Whole small fish as a rich calcium source. Br. J. Nutr. 2000, 83, 191-196. [CrossRef] [PubMed]

16. El-Beltagi, H.S.; El-Senousi, N.A.; Ali, Z.A.; Omran, A.A. The impact of using chickpea flour and dried carp fish powder on pizza quality. PLoS ONE 2017, 12, e0183657. [CrossRef]

17. Nawaz, A.; Xiong, Z.; Xiong, H.; Irshad, S.; Chen, L.; Wang, P.-k.; Ahsan, H.M.; Walayat, N.; Qamar, S.H. The impact of hydrophilic emulsifiers on the physico-chemical properties, microstructure, water distribution and in vitro digestibility of proteins in fried snacks based on fish meat. Food Funct. 2019, 10, 6927-6935. [CrossRef] [PubMed]

18. Nawaz, A.; Ali, S.W.; Irshad, S.; Irshad, F.; Ahmed, A.; Sharmeen, Z.; Khan, I. Effect of peeling and unpeeling on yield, chemical structure, morphology and pasting properties of starch extracted from three diverse potato cultivars of Pakistan. Int. J. Food Sci. Technol. 2019. [CrossRef]

19. Walayat, N.; Xiong, Z.; Xiong, H.; Moreno, H.M.; Niaz, N.; Ahmad, M.N.; Hassan, A.; Nawaz, A.; Ahmad, I.; Wang, P.-K. Cryoprotective effect of egg white proteins and xylooligosaccharides mixture on oxidative and structural changes in myofibrillar proteins of Culter alburnus during frozen storage. Int. J. Biol. Macromol. 2020, 158, 865-874. [CrossRef]

20. Allen, K.E.; Carpenter, C.E.; Walsh, M.K. Influence of protein level and starch type on an extrusion-expanded whey product. Int. J. Food Sci. Technol. 2007, 42, 953-960. [CrossRef]

21. Singh, B.; Rachna; Hussain, S.Z.; Sharma, S. Response Surface Analysis and Process Optimization of Twin Screw Extrusion Cooking of Potato-Based Snacks. J. Food Process. Preserv. 2015, 39, 270-281. [CrossRef]

22. Anton, A.A.; Fulcher, R.G.; Arntfield, S.D. Physical and nutritional impact of fortification of corn starch-based extruded snacks with common bean (Phaseolus vulgaris L.) flour: Effects of bean addition and extrusion cooking. Food Chem. 2009, 113, 989-996. [CrossRef]

23. Yang, C.; Zhong, F.; Douglas Goff, H.; Li, Y. Study on starch-protein interactions and their effects on physicochemical and digestible properties of the blends. Food Chem. 2019, 280, 51-58. [CrossRef]

24. Liu, T.; Hamid, N.; Kantono, K.; Pereira, L.; Farouk, M.M.; Knowles, S.O. Effects of meat addition on pasta structure, nutrition and in vitro digestibility. Food Chem. 2016, 213, 108-114. [CrossRef] [PubMed]

25. Abdel-Moemin, A.R. Healthy cookies from cooked fish bones. Food Biosci. 2015, 12, 114-121. [CrossRef]

26. Nawaz, A.; Li, E.; Khalifa, I.; Irshad, S.; Walayat, N.; Mohammed, H.H.H.; Zhang, Z.; Ahmed, S.; Simirgiotis, M.J. Evaluation of fish meat noodles: Physical property, dough rheology, chemistry and water distribution properties. Int. J. Food Sci. Tech. 2021, 56, 1061-1069. [CrossRef]

27. Walayat, N.; Xiong, Z.; Xiong, H.; Moreno, H.M.; Li, Q.; Nawaz, A.; Zhang, Z.; Wang, P.; Niaz, N. The effectiveness of egg white protein and $\beta$-cyclodextrin during frozen storage: Functional, rheological and structural changes in the myofibrillar proteins of Culter alburnus. Food Hydrocoll. 2020, 105, 105842. [CrossRef]

28. Phuhongsung, P.; Zhang, M.; Devahastin, S. Investigation on 3D printing ability of soybean protein isolate gels and correlations with their rheological and textural properties via LF-NMR spectroscopic characteristics. LWT 2020, 122, 109019. [CrossRef]

29. Li, C.; Liu, D.; Zhou, G.; Xu, X.; Qi, J.; Shi, P.; Xia, T. Meat quality and cooking attributes of thawed pork with different low field NMR T21. Meat Sci. 2012, 92, 79-83. [CrossRef]

30. Walayat, N.; Xiong, Z.; Xiong, H.; Moreno, H.M.; Nawaz, A.; Niaz, N.; Hu, C.; Taj, M.I.; Mushtaq, B.S.; Khalifa, I. The effect of egg white protein and $\beta$-cyclodextrin mixture on structural and functional properties of silver carp myofibrillar proteins during frozen storage. LWT 2021, 135, 109975. [CrossRef] 